\title{
Evaluation of the interaction between calcifying nanoparticles and human dental pulp cells: a preliminary investigation
}

This article was published in the following Dove Press journal:

International Journal of Nanomedicine

14 December 2010

Number of times this article has been viewed

\author{
Fang Yang ${ }^{1,4}$ \\ Jinfeng Zengl,4 \\ Wei Zhang ${ }^{2}$ \\ Xi Sun ${ }^{3}$ \\ Junqi Ling'
}

'Department of Operative Dentistry and Endodontics, Guanghua School and Hospital of Stomatology and Institute of Stomatological Research, Sun Yat-sen University, Guangzhou, China; ${ }^{2}$ National Neuroscience Institute, Singapore; ${ }^{3}$ School of Biological Engineering, Tianjin University of Science and Technology, Tianjin, China; ${ }^{4}$ These authors contributed equally to this work
Correspondence: Junqi Ling Department of Operative Dentistry and Endodontics, Guanghua School and Hospital of Stomatology and Institute of Stomatological Research, Sun Yat-sen University, Guangzhou, China Tel +86208386265 Email lingjq@mail.sysu.edu.cn

\begin{abstract}
Calcifying nanoparticles (CNPs, previously called nanobacteria) are self-propagating, cultivable macromolecular complexes. Their extraordinary characteristic is that they can aggregate carbonate apatite on their envelope from soluble calcium and phosphorus at physiologic concentrations and display cytotoxic effects on murine and human fibroblast cell lines. The question arises whether CNPs contribute to the degeneration of pulp tissue and thus result in clinically significant human dental pulp stones as nidies. This study evaluates CNPs' effects upon human dental pulp cells (HDPCs, the host cells in pulp tissue). We observed the ultrastructural variation of HDPCs attacked by CNPs. The spatial relationship of HDPCs and CNPs after coculture was also identified by immunofluroscence staining. Furthermore, it was verified by MTT viability assay that CNPs isolated from dental pulp stones exerted cytotoxic effect on HDPCs. Therefore, it could be concluded that the existence of CNPs might interfere with the normal physiologic function of the cells, and that might lead to dental pulp calcification. Elucidation of the cytotoxic characteristics of CNPs may offer a new perspective for understanding the etiology of human dental pulp stones.
\end{abstract}

Keywords: calcifying nanoparticles, nanobacteria, human dental pulp cells

\section{Introduction}

Calcifying nanoparticles (CNPs) are self-propagating, cultivable macromolecular complexes, previously called nanobacteria. ${ }^{1,2}$ The defining characteristics for CNPs are their ability to aggregate calcium and phosphate on their outer envelope at physiologic concentrations and conditions. ${ }^{3}$ Therefore it precipitates CNPs as a potential etiological factor involved in various pathological calcification diseases in human beings, such as kidney stones, ${ }^{4-7}$ calcified arteries, ${ }^{8-10}$ human breast cancer, ${ }^{11}$ and gallbladder stones. ${ }^{12,13}$

As there is a close relationship between CNPs and pathological calcification diseases in human beings, it is essential to clarify their effect on cultured mammalian cells. Çiftçioglu and Kajander ${ }^{14}$ firstly reported that four out of six nanobacteria isolates from different sera exerted a cytotoxic effect on 3 T6 fibroblasts verified by MTT viability assay, lactate dehygrogenase release, and direct microscopy. In nanobacteria-infected fibroblasts, electron microscopy revealed intra- and extracellular acicular crystal deposits, stainable with von Kossa staining and resembling calcospherules found in pathological calcification. ${ }^{3}$ The authors suggested that the nanobacteria had a special way of invading mammalian cells and were an important cause of cell vacuolization and poor growth. ${ }^{3,14}$ In 2009, Zhang et al ${ }^{15}$ claimed that gingival epithelial cells exposed to CNPs showed gross vacuolization and calcification occurring in intracellular 
vacuoles. This finding indicated CNPs' role in pathologic calcification of primary cultured human gingival epithelial cells in vitro.

Pulp stones are discrete calcifications and are among changes that include more diffuse pulp calcifications such as dystrophic calcification. ${ }^{16}$ Stones may exist freely within the pulp tissue or be attached to or embedded in dentine. ${ }^{17}$ More often than not, the existence of pulp stones may lead to narrowing or obstruction of the access to the apical point in the root canal; this is one of the most important factors leading to the failure of root canal therapy and loss of the teeth. We have discovered the close relationship between CNPs and dental pulp calcification in a former investigation, ${ }^{18}$ which indicated that CNPs might possibly play an important role in the formation of dental pulp stones. This finding significantly expanded our expectations to explain the formation of dental pulp calcification, of which the etiology until now was ambiguous. ${ }^{19-22}$ As far as we know today, pulp calcification is a type of chronic regressive degeneration of the pulp tissue; however, what leads to this devolution remains unclear. Dystrophic calcification is found to be of a variable degree, and this might originate from the impairment of the host cells. ${ }^{16}$ Therefore, it could be hypothesized that CNPs might have particular potency on human dental pulp cells (HDPCs). Those cells suffered from the encroachment after accumulative effect and resulted in a progressive deposition of calcified masses. To better understand CNPs' potential effect on cultured HDPCs based on this hypothesis, it is essential to evaluate the undermining mechanism of their co-interaction, qualitatively and quantitatively.

In this study, we observed the ultrastructural variation of HDPC attacked by CNPs through transmission electron microscopy (TEM) and the spatial relationship of HDPCs and CNPs after coculture by immunofluroscence staining. Furthermore, CNPs' cytotoxic effect on HDPCs was verified by MTT viability assay. From these experiments, it could be concluded that CNPs might invade HDPCs and exert biological effects on the attacking cells that might result in pulp calcification.

\section{Method and material Culture of HDPCs}

HDPCs (human dental pulp cells) were obtained from 22 healthy third molars (19- to 27-year-old patients) which were extracted during normal treatment at the Hospital of Stomatology, Sun Yat-sen University, Guangzhou, China. Protocol was reviewed and approved, and informed consents were obtained from the tissue donors with approval of the ethical committee of the Hospital of Stomatology, Sun
Yat-sen University. The primary HDPCs were cultured as previously reported by Gronthos et al. ${ }^{23}$ Teeth were placed into phosphate-buffered saline (PBS) and scored sagittally with a sterile diamond bur flushed with PBS. The pooling pulp tissue was collected and rinsed once in PBS and cut into $2 \mathrm{~mm}^{3}$ cubes using a dental surgical knife. Next, the fragmented pulp tissue was digested with $3 \mathrm{mg} \mathrm{mL}^{-1}$ type I collagenase (Sigma-Aldrich, St Louis, MO) and $4 \mathrm{mg} \mathrm{mL}^{-1}$ dispase (SigmaAldrich) for 30 minutes at $37^{\circ} \mathrm{C}$. The resultant suspension was then centrifuged to collect the released cells. These cells were subsequently cultured in Dulbecco's modified Eagle's medium (DMEM) (Gibco, Carlsbad, CA), supplemented with $10 \%$ fetal bovine serum (FBS) (Hyclone, Logan, UT), at $37^{\circ} \mathrm{C}$ in a humidified atmosphere of $5 \% \mathrm{CO}_{2}$. All experiments were performed on HDPCs between passages 5 and 8 .

\section{Culture of CNPs}

CNPs were isolated from the collected dental pulp stones as described in previous studies. ${ }^{4,18}$ Samples were immersed in $0.3 \mu \mathrm{g} \mathrm{mL}^{-1}$ tetracycline and then demineralized in $1 \mathrm{~mol} \mathrm{~L}^{-1}$ $\mathrm{HCl}$ for 30 minutes, then powdered and neutralized with $0.5 \mathrm{~mol} \mathrm{~L}^{-1}$ Tris (pH 10.5; Sigma-Aldrich). Suspensions were centrifuged at $14,000 \mathrm{~g}$ for 15 minutes in a Minispin Centrifuge and sterile-filtered through $0.22 \mu \mathrm{m}$ Millipore filters (Millipore, Billerica, MA). The filtrate was cultured in a flask containing DMEM with $10 \%$ FBS. Subcultures were carried out with a rubber scraper in serum-contained DMEM after 4 weeks of initial inoculation and subsequently after every day. Those after $2 \sim 3$ subcultures were scraped and harvested by centrifugation at 20,000 $\mathrm{g}$ for 45 minutes at $4^{\circ} \mathrm{C}$, washed with PBS (pH 7.2-7.4), and then resuspended by rigorous mixing for later use. The harvested CNP pallets were weighed and defined as the following concentration: $5.0 \mathrm{mg} \mathrm{mL}^{-1}, 2.5 \mathrm{mg} \mathrm{mL}^{-1}, 0.5 \mathrm{mg} \mathrm{mL}^{-1}$, attenuated by DMEM containing $2 \%$ r-FBS.

\section{Invasion of CNPs on HDPCs}

$100 \mu \mathrm{L}$ suspension of $2.5 \mathrm{mg} \mathrm{mL}^{-1} \mathrm{CNPs}$ was applied to the flask containing HDPCs and cocultured for 48 hours in the conditions for culturing mammal cells. Cells were digested by $0.25 \%$ trypsin (Invitrogen, Carlsbad, CA) and 0.02\% EDTA (Invitrogen) and collected by centrifugation to deposit cell pellets for the following analysis.

\section{Immunofluorescence confocal microscope observation}

Pallets of collected cells were fixed in 3.7\% formaldehyde for 15 minutes, and then washed twice with $0.01 \mathrm{~mol} \mathrm{~L}^{-1}$ 
PBS ( $\mathrm{pH} 7.2-7.4$ ) for 5 minutes, and then one drop was applied to the coverlip. Endogenous peroxidase was blocked with $3 \% \mathrm{H}_{2} \mathrm{O}_{2}$ in methanol for 15 minutes. After being blocked in 5\% bovine serum albumin for 30 minutes, cells were incubated with IgG1 class anti-CNP mAbs, 8D10 (Nanobac Oy, Kuopio, Finland) overnight at $4{ }^{\circ} \mathrm{C}$ and washed twice. The cells were then incubated in tris-buffered saline containing TRITC-labeled red-conjugated antimouse secondary antibodies (Wuhan Boshide, China) for 30 minutes at $37^{\circ} \mathrm{C}$ and washed twice. Subsequently, cells were applied with rabbit anti-human vimentin polyclonal antibody overnight and then with FITC-labeled secondary antibodies as above. Finally, coverlips were stained with $10 \mu \mathrm{g} \mathrm{mL}^{-1}$ Hoechst33258 (Sigma-Aldrich) for 10 minutes and then washed three times for 15 minutes in PBS. After being mounted, coverlips were viewed through LSM510 laser scanning confocal microscope (LSCM, Zeiss, Wetzlar, Germany) at a scanning thickness of $1 \mu \mathrm{m}$. Negative control went through the same process except that the coculture step was replaced with PBS.

\section{Transmission electron microscope observation}

Pellets were fixed in a $2.5 \%$ glutaraldehyde solution at $4{ }^{\circ} \mathrm{C}$ for 24 hours, and then post-fixed in $1 \%$ osmium tetroxide for 1 hour and dehydrated in a graded series of ethanol. Cells were embedded in epon-araldite. Ultrathin sections were cut with ultramicrotomy (LKB, Bromma, Sweden) and collected onto copper grids and stained with $2.5 \%$ uranyl acetate in absolute ethanol and lead citrate. All sections were examined by TEM (Hitachi H-600; Hitachi, Tokyo, Japan).

\section{Evaluation for cytotoxic effect}

The defined concentrations of CNPs (5.0, 2.5, and $0.5 \mathrm{mg} \mathrm{mL}^{-1}$ ) were used to determine the cytotoxic effect on cell proliferation. Firstly, HDPCs were plated at $2 \times 10^{4}$ cell $\mathrm{mL}^{-1}$ in 96-well plates and washed five times with $500 \mu \mathrm{L}$ PBS. Then cells were cultured again in a serum-free medium for at least 15 hours to remove any effect of the remaining steroid hormones. Secondly, media was replaced with fresh DMEM containing the indicated concentrations of CNPs through the $0.22-\mu \mathrm{m}$ Millipore filter. Each concentration contained six replicate wells and a control well. Finally, after 24, 48, and 72 hours of coculture, $20 \mu \mathrm{L} \operatorname{MTT}\left(5 \mathrm{~g} \mathrm{~L}^{-1}\right)$ (Sigma-Aldrich) was added to each well, and cells were incubated for 4 hours. Supernatant in each well was then removed and $150 \mu \mathrm{L}$ dimethyl sulfoxide (Sigma-Aldrich) was added to dissolve the formed formazan crystals for
10 minutes. Cell proliferation was detected quantitatively using a microplate reader (Infinit, Tecan, Austria) on optical density (OD) value at $490 \mathrm{~nm}$. After 72 hours' coculture, HDPCs attacked by CNPs were viewed under inverted phase contrast microscope (Axiovert 40; Zeiss).

Descriptive data are given as means \pm standard deviation. Data were analyzed using the SPSS statistical package (version 17.0; SPSS Inc., Chicago, IL). The multiple group means were compared by one-way analysis of variance (ANOVA), and differences were considered significant at $P<0.05$ level.

\section{Results}

\section{Immunostaining for the coculture}

The topological distributions of red-labeled CNPs, greenlabeled HDPCs, and blue-labeled nuclei of the HDPCs were visualized distinctly (Figure $1 \mathrm{~A}$ and $1 \mathrm{~B}$ ). The merged image (Figure 1C) clearly reflects the physical initial between the HDPCs and CNPs. It shows the initial invasion of CNPs on HDPCs. Some particles stuck to the outer membranes of the cells or invaded a specific site in the cytoplasm, or even entered the nucleus of the cells. For the negative control (Figure 1D and 1E), green and blue fluorescence signals were visible, but the red-labeled CNPs were small and trivial and were distributed in the noncell region. The merged image (Figure 1F) shows these red fluorescence signals had completely disappeared.
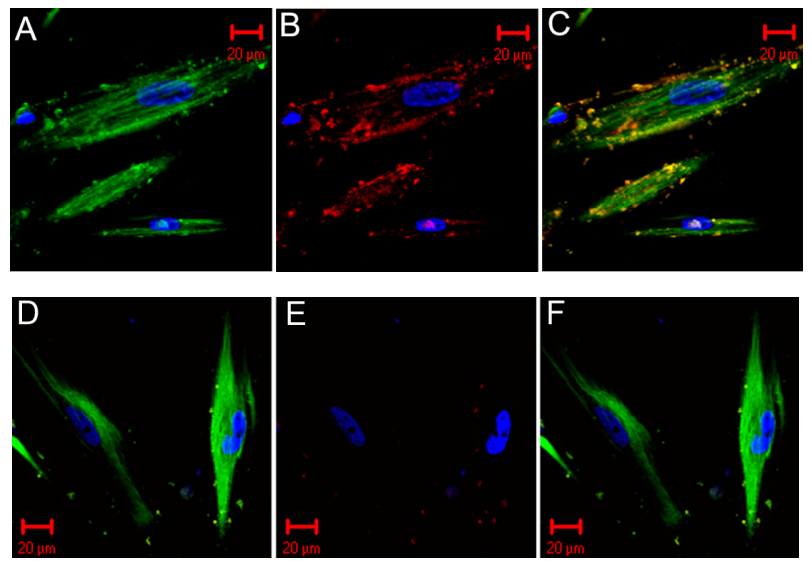

Figure I Immunofluorescent images. The first set is the positive immunofluorescent image for the invasion of CNPs and colocalization. The second set is the negative control. A, D) The green-conjugated secondary antibody recognized HDPCs and the Hoechst staining for blue-labeled nuclei of HDPCs. B, E) The blue-labeled nucleus of HDPCs and the red-conjugated secondary antibody recognized CNPs. C, F) The merged images of the above three colored signals. The invasion of CNPs on the cells is shown in $\mathbf{C}$. The red-labeled particles stick to the outer membranes of the cells or invade a specific site in the cytoplasm, or even enter the nucleus of the cells. In the negative control (E), the red-conjugated CNPs were seldom seen and were distributed in the noncell region. The merged view of $(\mathbf{F})$ shows the red signals had totally disappeared.

Abbreviations: CNPs, calcifying nanoparticles; HDPC, human dental pulp cell. 


\section{Ultrastructural variation observation}

The ultrastructure of the attacked HDPCs was observed by TEM. We discovered round or oval-shaped CNPs of diameter 200-400 nm, with a needle-like crystal crust. Particles stuck to the outer membranes of the cells (Figure 2A). A vacuolus containing mineralization crystals and a swollen mitochondrion can be detected in the enlarged picture (Figure 2B). Some particles were also located in the cytolysosome, phagocytozed by the cells. The affected cells displayed swollen mitochondria and disordered arrangement of the mitochondrial lamellar body (Figure 2C). The cells surrounded by CNPs displayed a state of necrosis and disintegration. The swollen and vacuolized mitochondria were released by the affected cells (Figure 2D). While in the control group, the ultrastructure of the cells was normal and the CNPs could not be found, either in the interior or exterior area of the HDPCs (Figure 2E).

\section{Cytotoxic effect of CNPs}

Cytotoxic effect of CNPs towards HDPCs was quantitatively analyzed by MTT viability-measurement test. MTT results showed that the survival and growth of HDPCs was nearly the same after 24 hours' coculture $(P>0.05)$, whereas these were obviously restrained after 48 hours' invasion by CNPs of high and medium concentration $(P<0.05)$. The effect

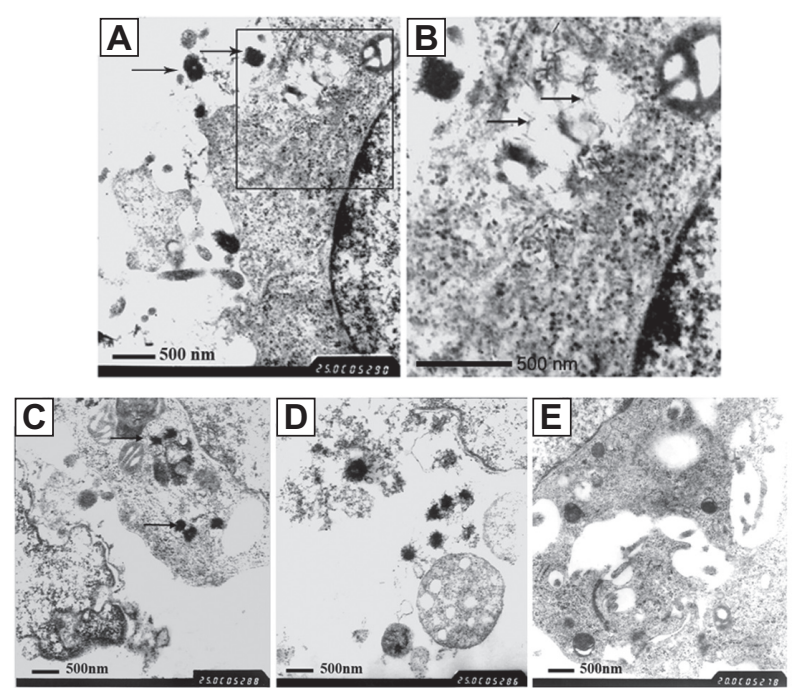

Figure 2 TEM images on the ultrastructure of the affected cells. A) The CNPs, diameter of $200-400 \mathrm{~nm}$, with needle-like crystals, stuck to the outer membranes of the cells. B) The enlarged scale of Figure 2A, showing the vacuolus containing mineralization crystals and swollen mitochondrion (TEM $\times 25,000)$. C) Some particles located in the cytolysosome, phagocytosed by the HDPCs. The affected cells show swollen mitochondria and a disordered arrangement of the mitochondrial lamellar body. D) Cells surrounded by CNPs, showing necrosis and disintegration. Released vacuolized mitochondria can be seen $(T E M \times 25,000)$. E) The negative control, showing the normal ultrastructure of the cells $(T E M \times 20,000)$.

Abbreviations: CNPs, calcifying nanoparticles; HDPC, human dental pulp cell; TEM, transmission electron microscopy. remained after 72 hours' invasion for the cells subjected to high concentration of CNPs $(P<0.05)$ (Table 1$)$.

Phase contrast microscopic observation showed clearly that those cells attacked by the high concentrations of CNPs displayed lowered cell density and abnormal morphology. Noticeable cell contraction and vacuolization could be detected in the cytoplasm of the affected cells (Figure 3A, 3B, and 3C), compared with the control (Figure 3D).

\section{Discussion}

In previous research, we provided microscopic and immunological evidence on CNPs' close relationship with dental pulp stones. ${ }^{18}$ However, this did not explain the CNPs' etiological role in the formation of the human dental pulp stones. In this study, we further investigated the biological effect exerted by CNPs on HDPCs to explain the undermining mechanism from a microcosmic point of view.

In this study, two to three subcultures of CNPs were chosen for two reasons. Firstly, subcultures increase the amount of the particles and therefore met the need for the whole experiment. Furthermore, this would not significantly affect the virulence characteristics for CNPs, for their reported cytotoxity decreases along with the subculture. ${ }^{14}$ For the preparation of CNPs, they were first scraped, ultrasonic conditioned, and well distributed to verify the correct concentrations and intensify their biological characteristics. To prevent contamination by other bacteria or fungi, all the particle suspensions were filtered through $0.22 \mu \mathrm{m}$ minispores in the coculture process.

It was reported that CNPs could infect several kinds of cells in human beings and adhere to $3 \mathrm{~T} 6$ cells within 15 minutes after their addition. These particles appeared to be in intracellular vacuoles, possibly endosomes and lysosomes. ${ }^{14}$ With the immunostaining technique, we constructed images to view cells, nuclei, and CNPs respectively by different fluorescence labels and furthermore used the merged view on CNP distribution in situ. It revealed for the first time the interaction between the CNPs and HDPCs. They could either stick to the outer membranes of the cells or invade a specific site in the cytoplasm, or even enter the nucleus of the cells. Immunofluorescent images proved the invasion of CNPs on HDPCs.

To identify the effect of this biological invasion, we observed the attacked cells through TEM. These round or oval-shaped particles, 200-400 $\mathrm{nm}$ in diameter, were seen. They closely resembled those found in other pathological calcification diseases. ${ }^{24-26}$ The attacked cells displayed abnormally, showing signs of vacuolar degeneration, membrane structural necrosis, mitochondrial swelling, etc. This indicated that the ultrastructure of the cells was severely damaged and 
Table I Effect of various concentrations of CNPs on the growth and survival of HDPCs

\begin{tabular}{lllll}
\hline Time & Control group & High concentration & Medium concentration & Low concentration \\
\hline 24-h OD & $0.6180 \pm 0.0269$ & $0.5954 \pm 0.0504$ & $0.6589 \pm 0.0974$ & $0.6033 \pm 0.0277$ \\
$48-\mathrm{h} \mathrm{OD}$ & $0.6333 \pm 0.0344$ & $0.3695 \pm 0.0177^{\mathrm{a}}$ & $0.5169 \pm 0.0208^{\mathrm{a}, \mathrm{b}}$ & $0.6063 \pm 0.0368$ \\
$72-\mathrm{h}$ OD & $0.5368 \pm 0.0644$ & $0.3837 \pm 0.0236^{\mathrm{a}}$ & $0.4847 \pm 0.0510$ & $0.5836 \pm 0.0168$ \\
\hline
\end{tabular}

Notes: ${ }^{p} p<0.05$, compared with the control group; ${ }^{b} P<0.05$, compared with the high-concentration group; Each value is the mean of the OD value of formazan dye measured by six experiments (mean $\pm \mathrm{SD}$ ).

Abbreviations: CNPs, calcifying nanoparticles; HDPC, human dental pulp cell; OD, optical density; SD, standard deviation.

physiologic function was in disorder after the infection. From the view of the particles located in the cytolysosome, it could be concluded that CNPs could invade HDPCs through a receptormediated endocytosis. There might exist a special cell adhesion molecule in the outer membrane of the CNPs that may induce the originally nonphagocytic human dental cells to become phagocytic and thus result in the impairment of the cells. ${ }^{14}$ Interestingly, we also detected vacuoli containing mineralization crystals, which indicated the cells' tendency for crystal deposits. It could be inferred that the existence of CNPs might promote the calcification as crystallization of the nuclei, which leads to the formation of biogenic apatite structures or mineralization degeneration of the cells. It reminded us that pathological calcification was not merely a passive consequence, but to some extent, occurred as a positive feedback loop of calcification and inflammation driving disease progression forward.

Quantitative assay of CNPs' cytotoxic effect was followed by MTT test to measure cell viability. As the metabolic activity of the CNPs was about 100th of that of common organisms, ${ }^{27}$ the environment for the coculture with different concentrations of CNPs could be regarded as similar and comparable. MTT results showed that the survival of HDPCs was obviously

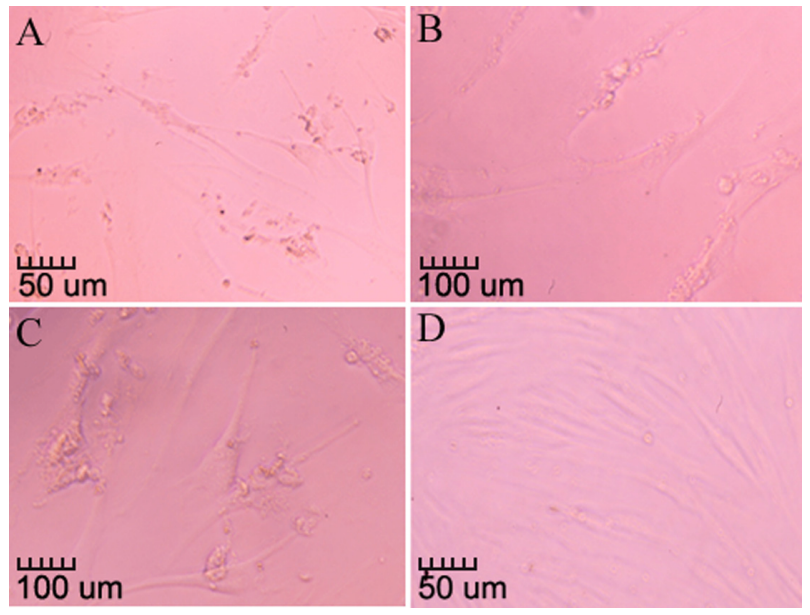

Figure 3 CNPs' cytotox effect on the morphology of HDPCs. A) The lower cell density and abnormal morphology $(100 \times)$. B, C) The enlarged details of the vacuolization in the cytoplasm of the attacked cells $(200 \times)$. D) The negative control (I00X).

Abbreviations: CNPs, calcifying nanoparticles; HDPC, human dental pulp cell. restrained after 48 hours' coculture for high and medium concentrations, and the effect remained after 72 hours' invasion by a high concentration of CNPs. This result was partially in agreement with the previous report that "the cytotoxity of CNPs was dependent on the concentration and the coculture time". ${ }^{14}$ We proposed two possible reasons contributing to this result. Firstly, to prevent other contamination, the addition of CNPs was filtered, not directly applied. Positive pressure in the filter process might reduce their cytotoxic effect, and thus the difference in the 24-hour period could not be found. Secondly, as HDPCs are located in a nutritional environment, the OD value we measured was the result of the proliferation and the inhibition effect. After 48 hours' coculture, the proliferation might outweigh the inhibition effect, so the difference was no longer significant for the cells cocultured with medium concentration of CNPs. Phase contrast microscopic observation on variations in the morphology and the amount of the cells proved once again the cytotoxic effect of CNPs on growing HDPCs.

To summarize, we report for the first time the interaction of CNPs with HDPCs. The presence of CNPs was proved as an active invader that interferes with the normal physiologic function of the cells and therefore might play a causative role in inducing calcification in the pulp tissue. However this is just a preliminary investigation; whether CNPs are nidies for calculi and contribute to the development of clinically significant human dental pulp stones needs to be further investigated, and more work is needed on whether it fulfills of Koch's postulates.

\section{Acknowledgments}

This work was supported by grants from the National Natural Science Foundation of China (No: 30471884).

\section{Disclosure}

The authors report no conflicts of interest in this work.

\section{References}

1. Kajander EO. Nanobacteria - propagating calcifying nanoparticles Lett Appl Microbiol. 2006;42(6):549-552.

2. Martel J, Young JD. Purported nanobacteria in human blood as calcium carbonate nanoparticles. Proc Natl Acad Sci U S A. 2008;105(14): 5549-5554. 
3. Kajander EO, Çiftçioglu N. Nanobacteria: an alternative mechanism for pathogenic intra- and extracellular calcification and stone formation. Proc Natl Acad Sci U S A. 1998;95(14):8274-8279.

4. Ciftçioglu N, Björklund M, Kuorikoski K, et al. Nanobacteria: an infectious cause for kidney stone formation. Kidney Int. 1999; 56(5):1893-1898.

5. García Cuerpo E, Olavi Kajander E, Ciftçioglu N, et al. Nanobacteria. An experimental neo-lithogenesis model. Arch Esp Urol. 2000; 53(4):291-303.

6. Ryall RL. The future of stone research: rummagings in the attic, Randall's plaque, nanobacteria, and lessons from phylogeny. Urol Res. 2008;36(2):77-97.

7. López-Brea M, Selgas R. Nanobacteria as a cause of renal diseases and vascular calcifying pathology in renal patients (endovascular lithiasis). Enferm Infecc Microbiol Clin. 2000;18(10):491-492.

8. Puskás LG, Tiszlavicz L, Rázga Z, et al. Detection of nanobacterialike particles in human atherosclerotic plaques. Acta Biol Hung. 2005;56(3-4):233-245.

9. Abul Y, Abul MH, Silay MS, et al. The role of nanobacteria in cardiac sarcoidosis. Med Hypotheses. 2007;68(5):1180.

10. Jelic TM, Chang HH, Roque R, et al. Nanobacteria-associated calcific aortic valve stenosis. J Heart Valve Dis. 2007;16(1):101-105.

11. Altundag K, Altundag $\mathrm{O}$, Akyurek S, et al. Possible association between nanobacteria and malignant microcalcifications in breast cancer. Breast J. 2006;12(3):287.

12. Wang L, Shen W, Wen J, et al. An animal model of black pigment gallstones caused by nanobacteria. Dig Dis Sci. 2006;51(6): 1126-1132.

13. Wen Y, Li YG, Yang ZL, et al. Detection of nanobacteria in serum, bile and gallbladder mucosa of patients with cholecystolithiasis. Chin Med J (Engl). 2005;118(5):421-424.

14. Çiftçioglu N, Kajander E. Interaction of nanobacteria with cultured mammalian cells. Pathophysiology. 1998;95(14):8274-8279.

15. Zhang SM, Tian F, Jiang XQ, et al. Evidence for calcifying nanoparticles in gingival crevicular fluid and dental calculus in periodontitis. J Periodontol. 2009;80(9):1462-1470.
16. Goga R, Chandler NP, Oginni AO. Pulp stones: a review. Int Endod J. 2008;41(6):457-468.

17. Johnson PL, Bevelander G. Histogenesis and histochemistry of pulpal calcification. J Dent Res. 1956;35(5):714-722.

18. Zeng J, Yang F, Zhang W, et al. Association between dental pulp stones and calcifying nanoparticles. Int J Nanomedicine. 2010; In press.

19. Hillmann G, Geurtsen W. Light-microscopical investigation of the distribution of extracellular matrix molecules and calcifications in human dental pulps of various ages. Cell Tissue Res. 1997;289(1): 145-154.

20. Robertson A, Lundgren T, Andreasen JO, et al. Pulp calcifications in traumatized primary incisors. A morphological and inductive analysis study. Eur J Oral Sci. 1997;105(3):196-206.

21. Sübay RK, Kaya H, Tarim B, et al. Response of human pulpal tissue to orthodontic extrusive applications. J Endod. 2001;27(8): 508-511.

22. Yamazoe T, Aoki K, Simokawa H, et al. Gene expression of bone matrix proteins in a calcified tissue appeared in subcutaneously transplanted rat dental pulp. J Med Dent Sci. 2002;49(1):57-66.

23. Gronthos S, Mankani M, Brahim J, et al. Postnatal human dental pulp stem cells (DPSCs) in vitro and in vivo. Proc Natl Acad Sci US A. 2000;97(25):13625-13630.

24. Zhou Z, Hong L, Shen X, et al. Detection of nanobacteria infection in type III prostatitis. Urology. 2008;71(6):1091-1095.

25. Tsurumoto T, Zhu D, Sommer AP. Identification of nanobacteria in human arthritic synovial fluid by method validated in human blood and urine using $200 \mathrm{~nm}$ model nanoparticles. Environ Sci Technol. 2008; 42(9):3324-3328.

26. Kajander EO, Ciftcioglu N, Aho K, et al. Characteristics of nanobacteria and their possible role in stone formation. Urol Res. 2003;31(2): 47-54.

27. Kajander EO, Kuronen I, Kari KA, et al. Nanobacteria from blood: the smallest culturable autonomously replicating agent on Earth. Proc SPIE Int. 1997;3111:420-428.
International Journal of Nanomedicine

\section{Publish your work in this journal}

The International Journal of Nanomedicine is an international, peerreviewed journal focusing on the application of nanotechnology in diagnostics, therapeutics, and drug delivery systems throughout the biomedical field. This journal is indexed on PubMed Central, MedLine, CAS, SciSearch $\AA$, Current Contents ${ }^{\circledR} /$ Clinical Medicine,

\section{Dovepress}

Journal Citation Reports/Science Edition, EMBase, Scopus and the Elsevier Bibliographic databases. The manuscript management system is completely online and includes a very quick and fair peer-review system, which is all easy to use. Visit http://www.dovepress.com/ testimonials.php to read real quotes from published authors. 